\title{
Postcolonial Theory
}




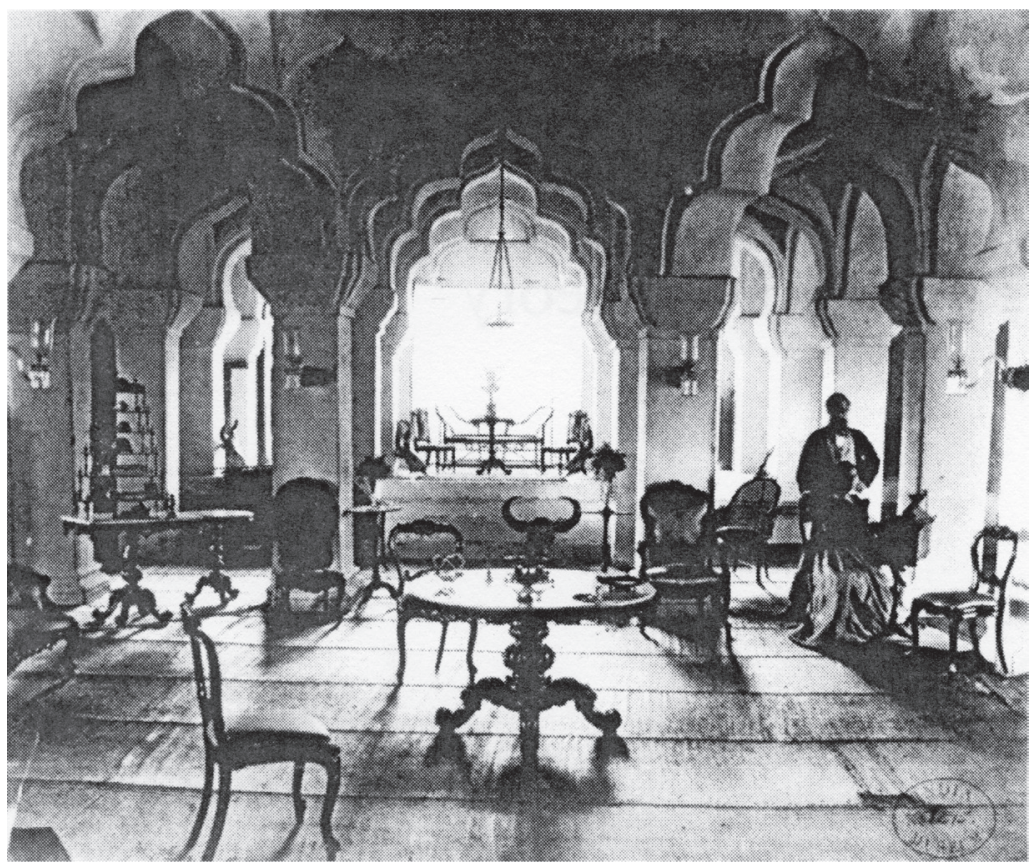

Interior of Tuncum, Madurai by Edmund David Lyon, Prints and Drawings Section of the Oriental and India Office Collections, British Library (OIOC photo 1001 [2975]) 


\title{
Postcolonial Theory \\ A Critical Introduction
}

\author{
Second Edition
}

\author{
Leela Gandhi
}

Columbia University Press

New York 


\section{Columbia University Press}

Publishers Since 1893

New York Chichester, West Sussex

cup.columbia.edu

Copyright (C) 2019 Columbia University Press

All rights reserved

\section{Library of Congress Cataloging-in-Publication Data \\ Names: Gandhi, Leela, 1966-}

Title: Postcolonial theory : a critical introduction / Leela Gandhi.

Description: Second Edition. I

New York : Columbia University Press, [2018] I

Previous edition: 1998. I Includes bibliographical references and index. Identifiers: LCCN 2018032553 (print) I LCCN 2018034095 (e-book) I

ISBN 9780231548564 (e-book) I ISBN 9780231178389

(cloth : acid-free paper) I ISBN 9780231178396 (paperback)

Subjects: LCSH: Postcolonialism.

Classification: LCC JV51 (e-book) | LCC JV51 .G36 2018 (print) |

$$
\text { DDC 325/.301-dc23 }
$$

LC record available at https://lccn.loc.gov/2018032553

Columbia University Press books are printed on permanent and durable acid-free paper.

Printed in the United States of America

Cover design: Elliott S. Cairns

Cover image: "Madura. The interior of the Tuncum." Photograph by Edmund David Lyon, c. 1868. British Library, London, UK / @ British

Library Board. All Rights Reserved / Bridgeman Images. 